\title{
Parapharyngeal abscess presenting as masticatory otorrhoea-persistent foramen tympanicum as a route of drainage: a case report
}

\author{
KH Lee *, FRCR, FHKCR, YL Li, MB, BS, FRCR, ML Yu, MB, ChB, FRCR \\ Department of Radiology, Queen Mary Hospital, Pokfulam, Hong Kong \\ *Corresponding author: viclkh88@gmail.com
}

Hong Kong Med J 2019;25:246-7

https://doi.org/10.12809/hkmj177027

\section{Case report}

A 26-year-old woman presented to the emergency department of Queen Mary Hospital in August 2014 with fever and right otorrhea following extraction of her right lower third molar 5 days previously. Physical examination revealed right buccal swelling, limited mouth opening, and pus-like discharge in the right external auditory canal (EAC) exacerbated by mastication. There was no hearing loss or facial nerve palsy. Otoscopy revealed granulation tissue and pus arising from the anterior wall of the inner right EAC.

Contrast-enhanced computed tomography scan showed a right parapharyngeal rim enhancing collection (Fig 1) tracking into the right temporomandibular fossa. Enhancing soft tissue was seen at the inner one-third of the right EAC. A bony defect was present at its anterior wall, compatible with a persistent foramen tympanicum (also known as foramen of Huschke), allowing communication

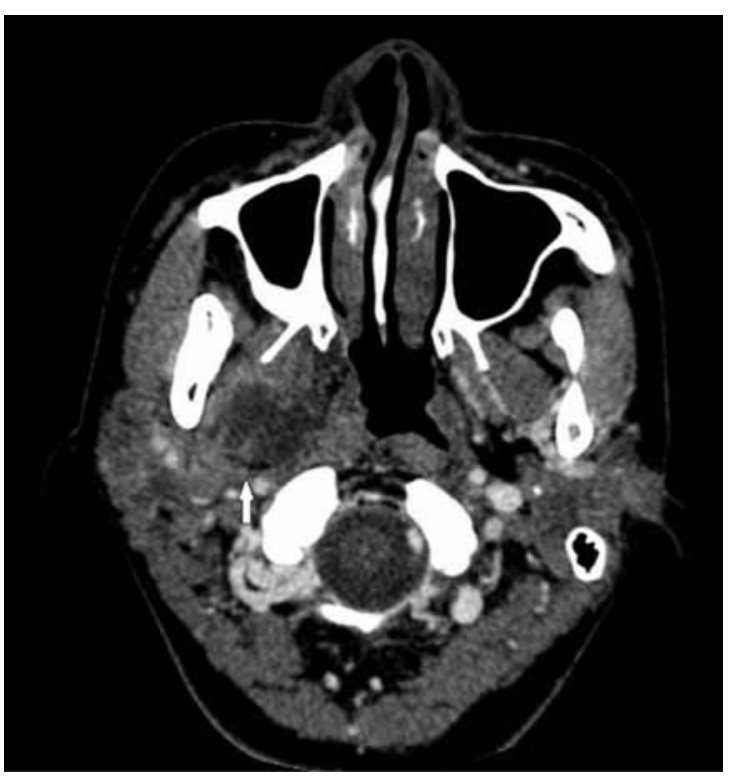

FIG I. Axial contrast-enhanced computed tomography of the neck of a 26-year-old woman showing rim-enhancing right parapharyngeal abscess extending to the right pterygomandibular space (white arrow) between the EAC and the temporomandibular fossa (Fig 2). Overall findings were compatible with right parapharyngeal abscess discharging via a persistent foramen tympanicum into the right EAC.

The patient was treated with a course of antibiotics in view of her stable condition and lack of airway compromise. The patient responded clinically and repeat computed tomography scan 1 week after initial presentation showed complete resolution of the right parapharyngeal abscess and enhancing soft tissue within the right EAC. Subsequent bacterial culture of the right ear discharge yielded Streptococcus anginosus, a common cause of oral infection.

\section{Discussion}

Parapharyngeal abscesses are deep cervical infections with potential serious complications such as shock, mediastinitis, jugular vein thrombosis, upper airway obstruction, and death. Tonsillitis and odontogenic infection are the most common aetiologies. The clinical presentation typically involves fever, neck pain, odynophagia, neck oedema, and upper airway obstruction. ${ }^{1}$

Otorrhea is typically caused by external or middle ear pathologies such as otitis. Otorrhoea as a presenting symptom for a neck abscess is highly unusual. In our literature review, only two cases were found. Biron et $\mathrm{al}^{2}$ described a patient with a submandibular abscess that tracked into the ipsilateral external auditory meatus via the parapharyngeal and masticator spaces. Pepato et $\mathrm{al}^{3}$ reported a case of lower third molar infection presenting as purulent ear discharge, with persistent foramen tympanicum found in a follow-up conebeam computed tomography study. The route of spread was postulated to be either via the Santorini fissures (the tiny defects in the anterior wall of the cartilaginous EAC) or via a persistent foramen tympanicum.

Persistent foramen tympanicum, first described by Emil Huschke in 1844, represents a failure of ossification of the tympanic part of the temporal bone and normally occurs from birth with completion by age 5 years. The foramen is located at 

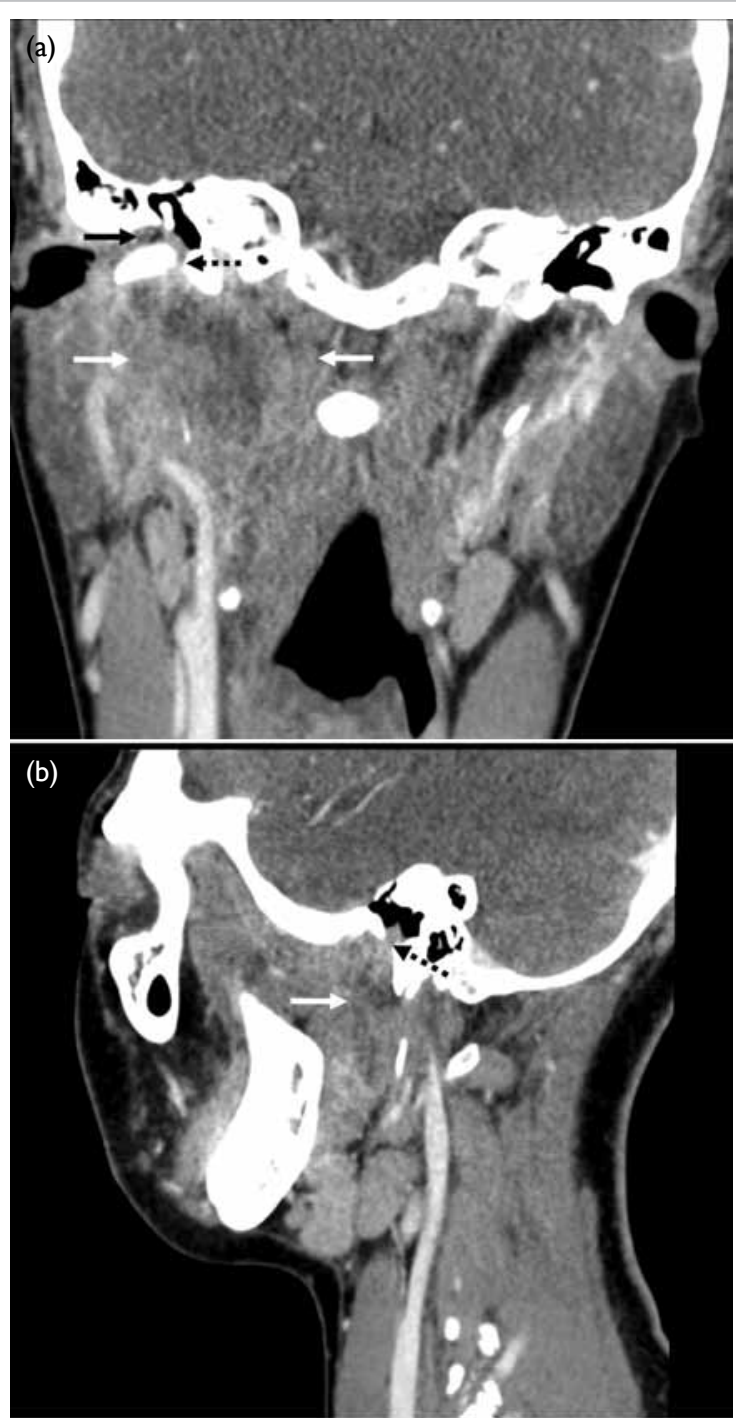

FIG 2. (a) Coronal and (b) sagittal computed tomography images of a 26-year-old woman demonstrating superior extension of the right parapharyngeal abscess (white arrows) into the right external auditory canal (EAC) via a bony defect at the anterior wall of the inner EAC, compatible with persistent foramen tympanicum (dashed black arrow).The enhancing soft tissue mass seen within the EAC corresponds to the granulation tissue visualised on otoscopy (black arrow). Mottled contents compatible with exudates can be seen within the right EAC

the anteroinferior aspect of the EAC, just posterior to the temporomandibular joint. Incidence is quoted from $4.6 \%$ to $22.7 \%$ based on radiological and cadaveric studies. ${ }^{4}$

The majority of individuals with the foramen are asymptomatic although various complications have been reported. Most are benign, such as salivation from the ear during mastication and spontaneous herniation of the temporomandibular joint into the EAC leading to otalgia and tinnitus. Iatrogenic middle ear injury is possible when the foramen is inadvertently traversed during temporomandibular joint arthroscopy. ${ }^{5}$ It is possible that the lack of bony integrity reduces mechanical resistance to pathological processes, such as the spreading of parapharyngeal abscess in our case. Parotid pleomorphic adenomas have also been reported to herniate through the foramen to present as an EAC mass.

To the best of our knowledge, this is the first case to provide direct radiological evidence of persistent foramen tympanicum as a route for drainage leading to masticatory otorrhoea. It is important for doctors to be aware of the clinical presentation to permit diagnosis and subsequent treatment.

\section{Author contributions}

All authors contributed to the concept, image acquisition, image and data interpretation, manuscript drafting, and critical revision for important intellectual content. All authors had full access to the data, contributed to the study, approved the final version for publication, and take responsibility for its accuracy and integrity.

\section{Conflicts of interest}

The authors have no conflicts of interest to disclose.

\section{Funding/support}

This research received no specific grant from any funding agency in the public, commercial, or not-for-profit sectors.

\section{Ethics approval}

Patient consent was obtained for the purpose of this case study.

\section{References}

1. Brito TP, Hazboun IM, Fernandes FL, et al. Deep neck abscesses: study of 101 cases. Braz J Otorhinolaryngol 2017;83:341-8.

2. Biron A, Halperin D, Sichel JY, Eliashar R. Deep neck abscess of dental origin draining through the external ear canal. Otolaryngol Head Neck Surg 2005;133:166-7.

3. Pepato AO, Yamaji MA, Sverzut CE, Trivellato AE. Lower third molar infection with purulent discharge through the external auditory meatus. Case report and review of literature. Int J Oral Maxillofac Surg 2012;41:380-3.

4. Akbulut N, Kursun S, Aksoy S, Kurt H, Orhan K. Evaluation of foramen tympanicum using cone-beam computed tomography in orthodontic malocclusions. J Craniofac Surg 2014;25:e105-9.

5. Nakasato T, Nakayama T, Kikuchi K et al. Spontaneous temporomandibular joint herniation into the external auditory canal through a persistent foramen tympanicum (Huschke): radiographic features. J Comput Assist Tomogr 2013;37:111-3. 